\title{
Influence of implantoplasty on stress distribution of exposed implants at different bone insertion levels
}

João Paulo Mendes TRIBST(a) Amanda Maria de Oliveira DAL PIVA(a) $^{(2)}$ Jamil Awad SHIBLI(b) Alexandre Luiz Souto BORGES(a) Rubens Nisie TANGO(a)

(a) Universidade Estadual Paulista - UNESP Institute of Science and Technology, Department of Dental Materials and Prosthodontics, São José dos Campos, SP, Brazil.

(b) Universidade de Guarulhos - UnG, Dental Research Division, Department of Periodontology and Oral Implantology, Guarulhos, SP, Brazil.

Declaration of Interests: The authors certify that they have no commercial or associative interest that represents a conflict of interest in connection with the manuscript.

Corresponding Author:

Amanda Maria de Oliveira Dal Piva

E-mail: amodalpiva@gmail.com

Submitted: May 05, 2017

Accepted for publication: Sep 19, 2017

Last revision: October 19, 2017

\begin{abstract}
This study evaluated the effect of implantoplasty on different bone insertion levels of exposed implants. A model of the Bone Level Tapered implant (Straumann Institute, Waldenburg, Switzerland) was created through the Rhinoceros software (version 5.0 SR8, McNeel North America, Seattle, WA, USA). The abutment was fixed to the implant through a retention screw and a monolithic crown was modeled over a cementation line. Six models were created with increasing portions of the implant threads exposed: $\mathrm{C} 1(1 \mathrm{~mm})$, C2 (2 mm), C3 (3 mm), C4 (4 mm), C5 (5 mm) and C6 (6 mm). The models were made in duplicates and one of each pair was used to simulate implantoplasty, by removing the threads (I1, I2, I3, I4, I5 and I6). The final geometry was exported in STEP format to ANSYS (ANSYS 15.0, ANSYS Inc., Houston, USA) and all materials were considered homogeneous, isotropic and linearly elastic. To assess distribution of stress forces, an axial load $(300 \mathrm{~N})$ was applied on the cusp. For the periodontal insert, the strains increased in the peri-implant region according to the size of the exposed portion and independent of the threads' presence. The difference between groups with and without implantoplasty was less than $10 \%$. Critical values were found when the inserted portion was smaller than the exposed portion. In the exposed implants, the stress generated on the implant and retention screw was higher in the models that received implantoplasty. For the bone tissue, exposure of the implant's thread was a damaging factor, independent of implantoplasty. Implantoplasty treatment can be safely used to control peri-implantitis if at least half of the implant is still inserted in bone.
\end{abstract}

Keywords: Finite Element Analyses; Dental Implants; Peri-Implantitis.

\section{Introduction}

Peri-implantitis is an inflammatory reaction with continuous loss of peri-implant insertion of dental implants. ${ }^{1}$ Studies have shown that in implants with rough contaminated surfaces the progression of this pathology is accelerated. ${ }^{2,3}$ Exposed threads in contact with the oral environment provide a favorable niche to bacteria adherence. The inflammation process promotes progressive bone loss, thus exposing more threads and allowing more bacterial proliferation. 
The main therapies to control peri-implantitis are resective or regenerative surgeries. ${ }^{2}$ Resection therapy removes the inflammatory tissue surrounding the contaminated implant surface. ${ }^{3}$ Regenerative therapy uses bone grafts and membranes seeking to reconstruct the peri-implant bone tissue. ${ }^{4}$ Resection therapy is known for being a more effective approach than non-surgical techniques, which have failed to demonstrate clinical efficacy in solving peri-implantitis. ${ }^{5}$ As disadvantages, the resection surgery does not reduce pathogenic bacteria ${ }^{2}$ and the regeneration procedure does not guarantee recuperation of lost peri-implant bone. ${ }^{6}$ Resection procedures have the purpose of modifying the implant surface, making it smooth and polished, which seem to achieved favorable biological results in stabilizing bone loss. ${ }^{7,8}$ This procedure performed on the implant surface is called "implantoplasty", and aims to facilitate the cleaning of exposed threads.

Implantoplasty is a successful therapy for peri-implantitis and inflammation. ${ }^{3}$ However, it reduces the diameter and the wall thickness of the implant, ${ }^{9}$ therefore the reliability of this treatment is still undefined. ${ }^{2}$ Until now, there is no information in the literature about the influence of this or any other therapy on different implant insertions levels. ${ }^{10}$ Therefore, it is not known the minimum level of bone insertion that allows implantoplasty to be done without causing damaging stress to the bone. The purpose of this study was to evaluate the effect of implantoplasty on different insertion levels of exposed implants with a specific macro-design. The hypotheses of this study were: implantoplasty does not interfere in the mechanical behavior of implants (a), retention screws (b) or bone microstrain (c) at different levels of implant exposure.

\section{Methodology}

Models were created during pre-processing using the Rhinoceros software (version 5.0 SR8, McNeel, Seattle, USA). A previously validated ${ }^{11}$ monolithic crown (Figure 1A) was modeled over a cementation line (Figure 1B) to allow an implant-supported prosthesis. Then, a retention screw (Figure 1C) was modeled to fix the abutment with $5 \times 5.5 \mathrm{~mm}$ (Figure 1D) to the implant. A Boolean difference Rhinoceros command that trims the shared areas of selected poly surfaces with another set of poly surfaces was used for the implant internal walls that have contact with the abutment's external walls. A model of the Bone Level Tapered implant (Straumann Institute, Waldenburg, Switzerland) with $4.1 \times 10 \mathrm{~mm}$ was created following the implants' characteristics such as size, shape and absence of external defects (Figure 1E). Initially, lines were constructed following thread dimensions so that each face of the model was obtained. After creating the surfaces, the models were fixed and a volumetrically solid cylindrical implant was formed. An illustration of the final model is shown in Figure 1F.

A

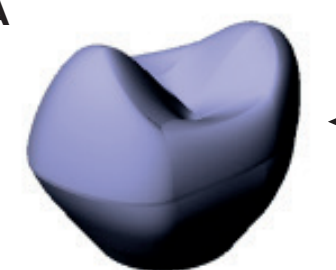

B

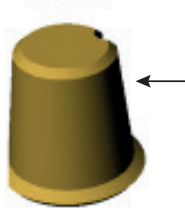

C

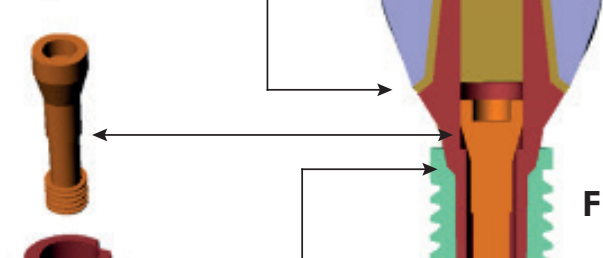

D

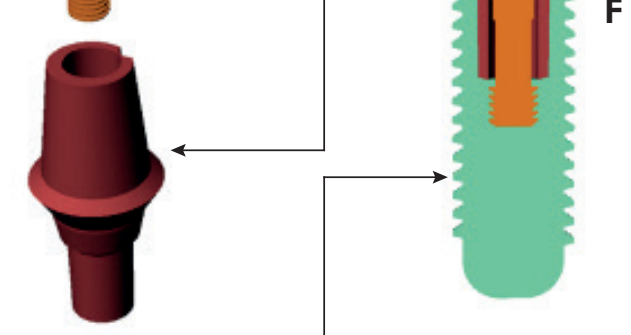

$\mathbf{E}$

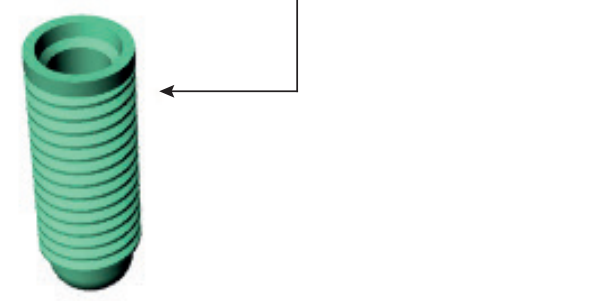

Figure 1. A) Monolithic crown; B) Cement layer; C) Retention Screw; D) Abutment; E) Implant Fixture; F) Final model. 
The bone (cortical and cancellous) was created based on a Transversal section of an edentulous human jaw from the São Paulo State University (Unesp) at São José dos Campos (SP). The implant was installed in the center of the ridge with the ideal cortical level as the control group (C0). Six models were created containing progressively exposed implant threads: C1 (1 mm), C2 (2 mm), C3 (3 mm), C4 (4 mm), C5 $(5 \mathrm{~mm})$ and C6 $(6 \mathrm{~mm})$. Then, the models with the exposed implants were duplicated to simulate implantoplasty by removing the exposed threads, so that the implants had their diameter decreased. Thirteen models were obtained in total (Figure 2).

The final geometry was exported in STEP format to ANSYS 15.0 (ANSYS Inc., Houston, USA). All materials were considered homogeneous, isotropic and linearly elastic. Respective Elastic Modulus and Poisson's ratio are shown in Table..$^{12,13,14,15}$ The mesh convergence test was used and the ideal size of the elements was $0.3 \mathrm{~mm}$. All contacts were considered perfectly bonded, without any loss of torque or rotational misfit.

An axial load of $300 \mathrm{~N}$ was applied on the cusp of the models using a ball, simulating cusp deflection. ${ }^{11}$ For the fixed condition, bone tissue was prevented from moving in the Z-axis to ensure restricted movement and enable to measure the Strain generated inside the jaw.

\section{Results}

The results were generated according to von Mises stress criteria for a non-ductile solid. The generated microstrain was evaluated for a human bone model.

For the implant analysis, the stress was displayed in color scales and was concentrated on the external
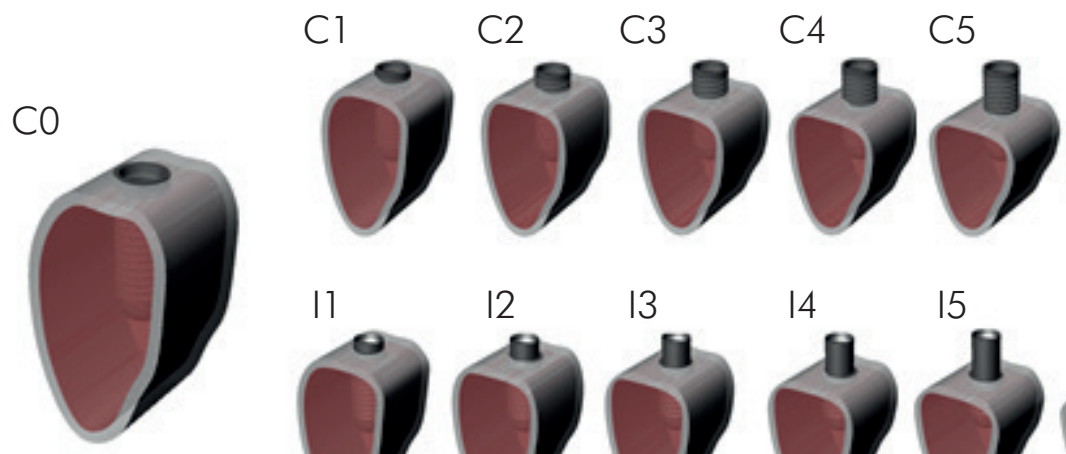

C6
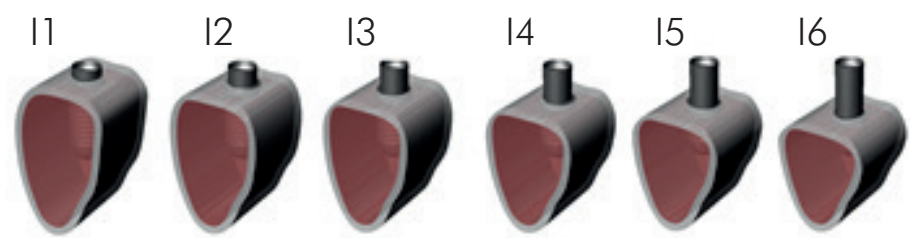

Figure 2. Group distribution according to exposed implant and presence of implantoplasty: C0) Control Group; C1) $1 \mathrm{~mm}$ of exposed implant; 11) $1 \mathrm{~mm}$ of exposed implant submitted to implantoplasty; C2) $2 \mathrm{~mm}$ of exposed implant; I2) $2 \mathrm{~mm}$ of exposed implant submitted to implantoplasty; C3) $3 \mathrm{~mm}$ of exposed implant; 13) $3 \mathrm{~mm}$ of exposed implant submitted to implantoplasty; C4) $4 \mathrm{~mm}$ of exposed implant; 14) $4 \mathrm{~mm}$ of exposed implant submitted to implantoplasty; C5) $5 \mathrm{~mm}$ of exposed implant; 15) $5 \mathrm{~mm}$ of exposed implant submitted to implantoplasty; C6) $6 \mathrm{~mm}$ of exposed implant; 16) $6 \mathrm{~mm}$ of exposed implant submitted to implantoplasty.

Table. Distribution of mechanical properties of the materials used in FEA analysis.

\begin{tabular}{lcc}
\hline Material/Structure & Elastic Modulus (GPa) & Poisson's ratio \\
\hline Titanium & 110 & $0.33^{12}$ \\
Lithium disilicate & 95 & $0.3^{13}$ \\
Resin cement & 5.1 & $0.27^{14}$ \\
Cancellous bone & 1.37 & $0.30^{15}$ \\
Cortical bone & 13.7 & $0.30^{15}$ \\
\hline
\end{tabular}


surface in contact with the cortical bone for all groups (Figure 3). The maximum values in MPa were plotted on a graph. Groups with the same portion of exposed implant exhibited increased stress when subjected to implantoplasty. For fixing screws, the stress concentration and the maximum value also increased with larger exposed portions and smaller diameters (Figure 4).

Strains increased in the peri-implant tissue according to increasing amounts of exposed implant surface and independently of the presence of threads (Figure 5). This strain pattern is possibly damaging in the red areas of the graphs. The difference between groups with and without implantoplasty with the same bone height was less than 10\%. In Figure 5, the results show that initial bone loss results in smaller maximum generated strains. A critical result was observed when the inserted portion of the implant was smaller than the exposed portion.

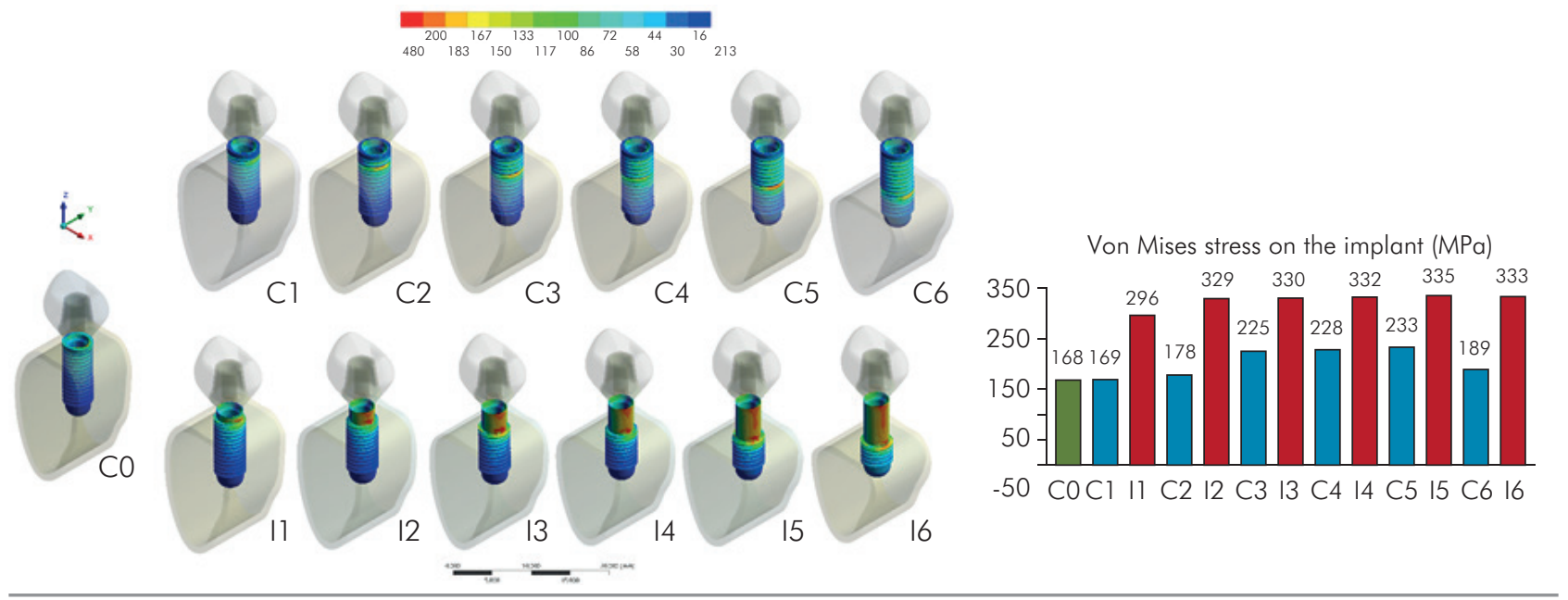

Figure 3. Stress distribution on the implant according to von Mises stress criteria for all groups.

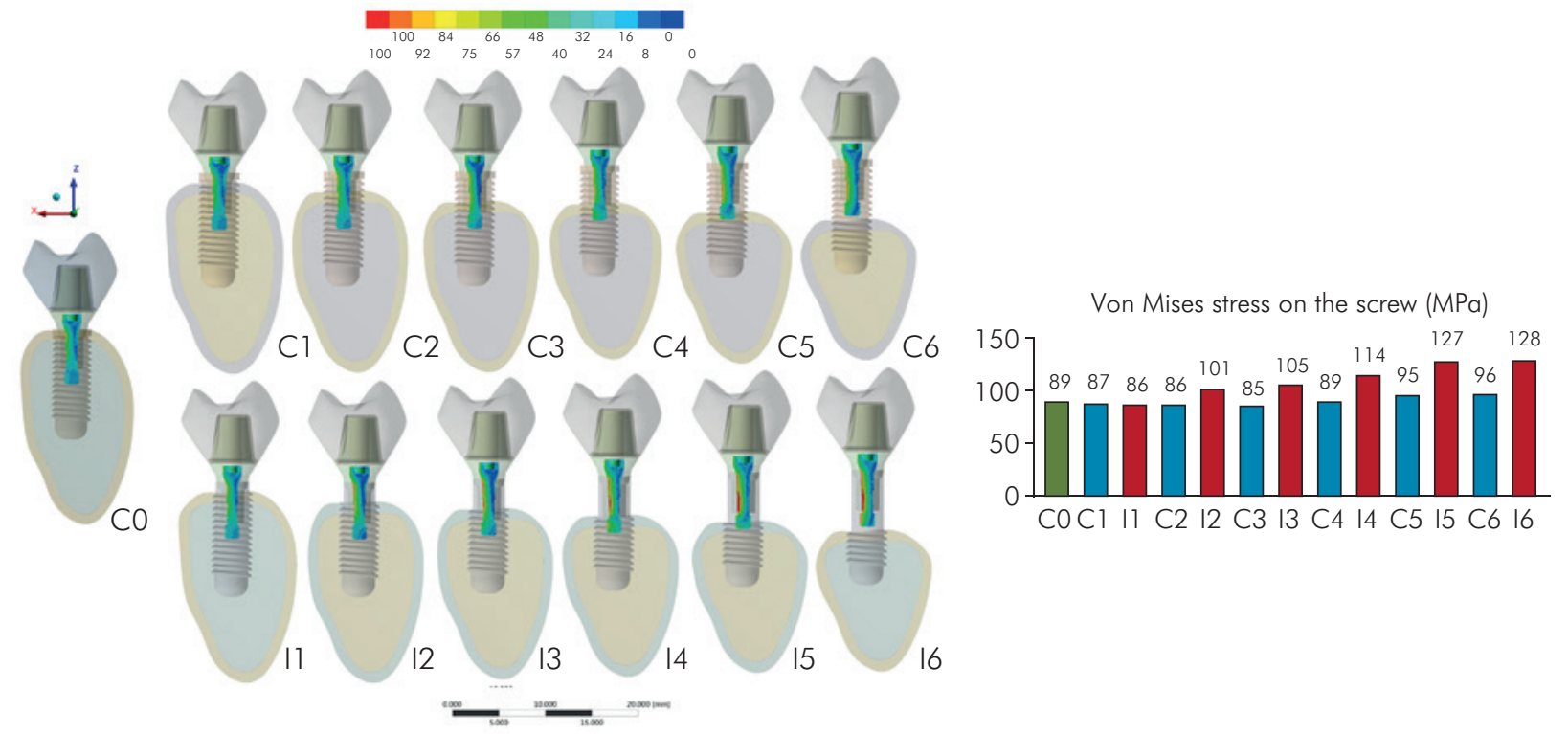

Figure 4. Stress distribution on the retention screw according to von Mises stress criteria for all groups. 


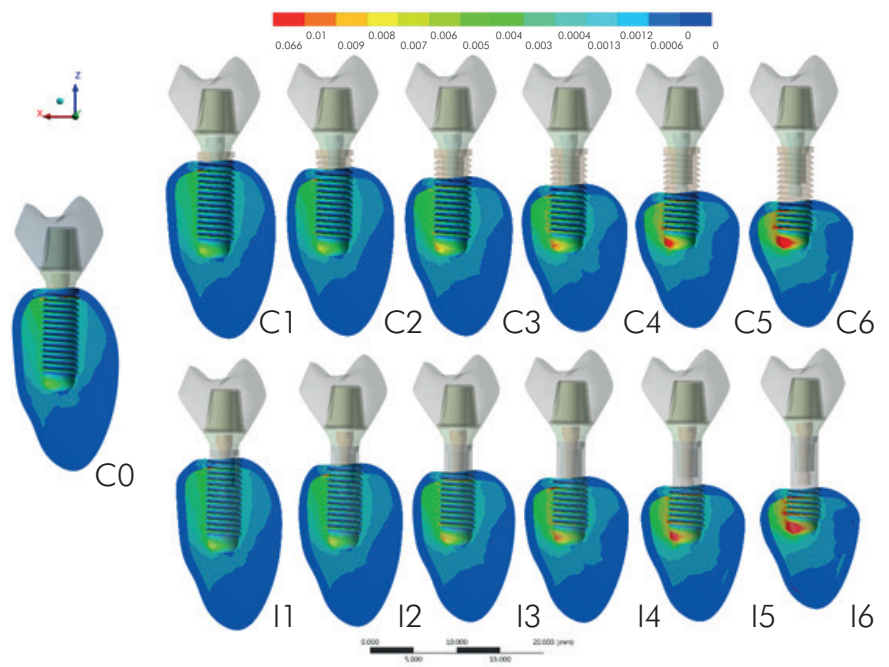

Bone Micro Strain

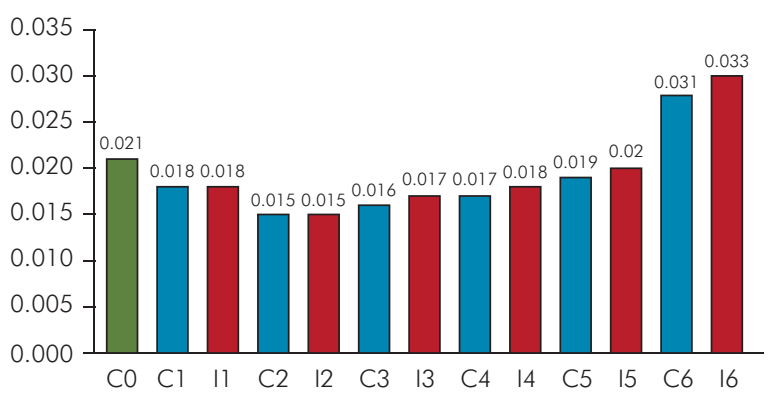

Figure 5. Micro strain on the bone tissue for all groups.

\section{Discussion}

In the present study, different implant insertion levels were simulated to evaluate the influence of implantoplasty on the implants, retention screws and the surrounding bone. Based on the results the first and second hypotheses were accepted. The stress concentration on the implant (Figure 3) and screw (Figure 4) increased proportionally to the amount of exposed surface.

Previous studies are inconclusive about the reduction ${ }^{16}$ or not ${ }^{9}$ of the implant's resistance by implantoplasty when $5 \mathrm{~mm}$ of the implant are exposed. In the present study, we observed that implantoplasty increases stress concentration on the implant and screw, indicating that the critical stress point of the material will be achieved earlier, thus leading to treatment failure. However, implantoplasty is an effective clinically proven procedure and can be applied in association with resection therapy in advanced cases of advanced peri-implantitis (PD $>5 \mathrm{~mm}$ and bone loss $>5 \mathrm{~mm}$ ), ${ }^{7,17,18}$ Thus, the assessment of stress forces generated in the system is more valuable to understand and prevent unwanted masticatory forces when implantoplasty is required, since peri-implantitis is a condition associated to the diameter of the implant, which is not taken into consideration when choosing the implant to be installed, as suggested by a previous study. ${ }^{10}$
The present study evaluated the biomechanical behavior of structures on a 3D-FEA in a single model of dental implant with a specific macro-design. This method has advantages over in vitro studies, such as being less expensive, allowing standardized samples, and having less factors influencing the results. ${ }^{19}$ In addition, it allows inferences in a simulated bone tissue with the same properties of an in vivo tissue, eliminating the use of resins for inclusion of implants and possible failures by the operator. Compared to other in vitro methodologies, FEA produces results not only for a surface (photoelastic) but also for a punctual area (strain gauge), ${ }_{1}^{19,20}$ being the only method to show the strain distribution inside the bone tissue, as commonly used. ${ }^{21,22,23,24}$ To examine FEA results on implants, von Mises criteria was chosen to observe the regions with higher stress concentration. ${ }^{25}$ To the best of the author's knowledge, there are no studies available in the literature associating implantoplasty and different heights of exposed implants. Although implantoplasty can be considered a rescue treatment for advanced peri-implant lesions, the present study has some limitations: an ideal condition was simulated, excluding the simulation of masticatory loads; the macro-design of the implant used have shorter threads when compared with other designs that present self-tapping threads with more effective cutting flow effect. These results should not be extrapolated to the clinical situation as the limitations could have 
minimized the negative effects of reducing the implant thickness. Further studies should be developed to approximate these results to clinical situations. ${ }^{26}$

This study also found that implant exposure is harmful to the bone, regardless of the removal of the exposed threads (Figure 5), thus rejecting the third hypothesis. In Figure 5, the results show that implant exposure decreases maximum strain values on the bone up to $5 \mathrm{~mm}$. This can be justified by a change of the fulcrum between bone and implant.

Despite the decline in the maximum absolute value, the range of colors shows that the medium stress area increased according to increased exposure of implants; this suggests that the medullary bone tissue tends to dissipate the load rather than concentrate it on a single point. Therefore, microstrain values are within a physiological range for up to $5 \mathrm{~mm}$ exposure. ${ }^{27}$ In I6 and C6 groups, which simulated a more damaging situation of an exposed implant, there was a large increase in the

\section{References}

1. Salvi GE, Zitzmann NU. The effects of anti-infective preventive measures on the occurrence of biologic implant complications and implant loss: a systematic review. Int J Oral Maxillofac Implants. 2014;29 Suppl:292-307. https://doi.org/10.11607/jomi.2014suppl.g5.1

2. Mahato $N, W_{U} X$, Wang L. Management of peri-implantitis: a systematic review, 2010-2015. Springerplus. 2016;5(1):105. https://doi.org/10.1186/s40064-016-1735-2

3. Romeo E, Lops D, Chiapasco M, Ghisolfi M, Vogel G. Therapy of peri-implantitis with resective surgery. A 3-year clinical trial on rough screw-shaped oral implants. Part II: radiographic outcome. Clin Oral Implants Res. 2007;18(2):179-87. https://doi.org/10.1111/j.1600-0501.2006.01318.x

4. Claffey N, Clarke E, Polyzois I, Renvert S. Surgical treatment of peri-implantitis. J Clin Periodontol. 2008;35(8 Suppl):316-32. https://doi.org/10.1111/j.1600-051X.2008.01277.x

5. Lindhe J, Meyle J. Peri-implant diseases: Consensus Report of the Sixth European Workshop on Periodontology. J Clin Periodontol. 2008;35(8):282-5. https://doi.org/10.1111/j.1600-051X.2008.01283.x

6. Renvert S, Polyzois I, Maguire R. Re-osseointegration on previously contaminated surfaces: a systematic review. Clin Oral Implants Res. 2009;20(4 Suppl):216-27. https://doi.org/10.1111/j.1600-0501.2009.01786.x maximum microstrain value in the bone tissue, reaching an undesired threshold (above 3000). In this situation, the osseointegration loss is dependent upon mechanical factors and not just on microbiological ones. Therefore, it is suggested that implant loss will occur, even if the infection is controlled.

\section{Conclusion}

Within this study's limitations, it may be concluded that:

In exposed implants, the stress generated on the implant and retention screw is increased if implantoplasty is performed;

For the bone tissue, exposure of the implant thread is a negative factor and is independent of implantoplasty;

For this specific macro-design, implantoplasty treatment can be performed to control peri-implantitis if at least half of the implant is still inserted in bone.
7. Dohan Ehrenfest DM, Coelho PG, Kang BS, Sul YT, Albrektsson T. Classification of osseointegrated implant surfaces: materials, chemistry and topography. Trends Biotechnol. 2010;28(4):198-206. https://doi.org/10.1016/i.tibtech.2009.12.003

8. Ramel CF, Lüssi A, Özcan M, Jung RE, Hämmerle CH, Thoma DS. Surface roughness of dental implants and treatment time using six different implantoplasty procedures. Clin Oral Implants Res. 2016;27(7):776-81. https://doi.org/10.1111/clr.12682

9. Chan HL, Oh WS, Ong HS, Fu JH, Steigmann M, Sierraalta $\mathrm{M}$ et al. Impact of implantoplasty on strength of the implant-abutment complex. Int J Oral Maxillofac Implants. 2013;28(6):1530-5. https://doi.org/10.11607/jomi.3227

10. Shibli J, Ivanovski S, Park YB, Alarcon M, Cheung KM, Duncan $\mathrm{W}$ et al. Implants: peri-implant (hard and soft tissue) interactions in health and disease: the impact of explosion of implant manufacturers. J Int Acad Periodontol. 2015;17(1 Suppl):71-3.

11. Costa A, Xavier T, Noritomi P, Saavedra G, Borges A. The influence of elastic modulus of inlay materials on stress distribution and fracture of premolars. Oper Dent. 2014;39(4):E160-70. https://doi.org/10.2341/13-092-L

12. Verri FR, Santiago Júnior JF, Almeida DA, Verri AC, Batista VE, Lemos CA et al. Three-dimensional finite element analysis of anterior single implant-supported prostheses with different bone anchorages Sci World J. 2015;2015:321528. https://doi.org/10.1155/2015/321528 
13. Tian $Y, M u Y$, Setzer FC, Lu H, Qu T, Yu Q. Failure of fiber posts after cementation with different adhesives with or without silanization investigated by pullout tests and scanning electron microscopy. J Endod. 2012;38(9):1279-82. https://doi.org/10.1016/j.joen.2012.06.022

14. Zarone F, Sorrentino R, Apicella D, Valentino B, Ferrari M, Aversa R et al. Evaluation of the biomechanical behavior of maxillary central incisors restored by means of endocrowns compared to a natural tooth: a 3D static linear finite elements analysis. Dent Mater. 2006;22(11):1035-44. https://doi.org/10.1016/i.dental.2005.11.034

15. Madfa AA, Kadir MR, Kashani J, Saidin S, Sulaiman E, Marhazlinda J et al. Stress distributions in maxillary central incisors restored with various types of post materials and designs. Med Eng Phys. 2014; 36(7):962-7. https://doi.org/10.1016/i.medengphy.2014.03.018

16. Gehrke SA, Aramburú Júnior JS, Dedavid BA, Shibli JA. Analysis of Implant Strength After Implantoplasty in Three Implant-Abutment Connection Designs: An In Vitro Study. Int J Oral Maxillofac Implants. 2016;31(3):e65-70. https://doi.org/10.11607/jomi.4399

17. Schwarz F, Hegewald A, John G, Sahm N, Becker J. Four-year follow-up of combined surgical therapy of advanced peri-implantitis evaluating two methods of surface decontamination. J Clin Periodontol. 2013 Oct;40(10):962-7. https://doi.org/10.1111/jcpe.12143

18. Schwarz F, John G, Sahm N, Becker J. Combined surgical resective and regenerative therapy for advanced peri-implantitis with concomitant soft tissue volume augmentation: a case report. Int J Periodontics Restorative Dent. 2014;34(4):489-95. https://doi.org/10.11607/prd.1794

19. Tribst JP, Dal Piva AM, Borges AL. Biomechanical tools to study dental implants: A literature review. Braz Dent Sci. 2016;19(4):5-11. https://doi.org/10.14295/bds.2016.v19i4.1321
20. Pesqueira AA, Goiato MC, Filho HG, Monteiro DR, Santos DM, Haddad MF et al. Use of stress analysis methods to evaluate the biomechanics of oral rehabilitation with implants. J Oral Implantol. 2014;40(2):217-28. https://doi.org/10.1563/AAID-JOI-D-11-00066

21. Greco GD, Jansen WC, Landre Junior J, Seraidarian PI. Stress analysis on the free-end distal extension of an implant-supported mandibular complete denture. Braz Oral Res. 2009;23(2):182-9. https://doi.org/10.1590/S1806-83242009000200014

22. Camargos Gde V, Sotto-Maior BS, Silva WJ, Lazari PC, Del Bel Cury AA. Prosthetic abutment influences bone biomechanical behavior of immediately loaded implants. Braz Oral Res. 2016;30(1):e65. https://doi.org/10.1590/1807-3107BOR-2016.vol30.0065

23. Tribst JPMT, Morais DC, Alonso AA, Dal Piva AMO, Borges ALS. Comparative three-dimensional finite element analysis of implant-supported fixed complete arch mandibular prostheses in two materials. J Indian Prosthodont Soc. 2017;17(3):255-60. https://doi.org/10.4103/jips.jips_11_17

24. Dal Piva AMO, Tribst JPM, Souza ROAE, Borges ALS. Influence of alveolar bone loss and cement layer thickness on the biomechanical behavior of endodontically treated maxillary incisors: a 3-dimensional finite element analysis. J Endod. 2017;43(5):791-5. https://doi.org/10.1016/i.joen.2016.11.020

25. Değer Y, Adigüzel Ö, Yiğit Özer S, Kaya S, Seyfioğlu Polat Z, Bozyel B. Evaluation of temperature and stress distribution on 2 different post systems using 3-dimensional finite element analysis. Med SciMonit. 2015;21:3716-172. https://doi.org/10.12659/MSM.896132

26. Wang G, Zhang S, Bian C, Kong H. Verification of finite element analysis of fixed partial denture with in vitro electronic strain measurement. J Prosthodont Res. 2016;60(1):29-35. https://doi.org/10.1016/i.jpor.2015.08.003

27. Frost HM. Wolff's law and bone structural adaptations to mechanical usage: an overview for clinicians. Angle Orthod. 1994;64(3):175-88. https://doi.org/10.1043/00033219(1994)064<0175:WLABSA > 2.0.CO;2 